\title{
EFEKTIVITAS PROGRAM PENGEMBANGAN DESTINASI PARIWISATA DI KABUPATEN CIAMIS (STUDI PADA OBJEK WISATA SITU LENGKONG)
}

\section{TOURISM DESTINATION DEVELOPMENT PROGRAM EFFECTIVENESS IN CIAMIS DISTRICT (A STUDY OF SITU LENGKONG ATTRACTIONS)}

\author{
Nina Marlina; Heru Nurasa; Ramadhan Pancasilawan \\ ninamarlina854@gmail.com; heru.nurasa@unpad.ac.id; \\ ramadhan.pancasilawan@unpad.ac.id \\ Program Studi Administrasi Publik \\ Fakultas Ilmu Sosial dan Ilmu Politik \\ Universitas Padjadjaran \\ Bandung, Indonesia
}

\begin{abstract}
ABSTRAK
Skripsi ini berupaya menyajikan hasil penelitian yang menggambarkan bagaimana Efektivitas Program Pengembangan Destinasi Pariwisata di Kabupaten Ciamis (Studi Pada Objek Wisata Situ Lengkong). Penelitian ini dilatarbelakangi oleh adanya penurunan Pendapatan Asli Daerah (PAD) Kabupaten Ciamis dari sektor pariwisata setelah Pangandaran memisahkan diri menjadi Daerah Otonomi Baru. Dengan begitu maka Pemerintah Kabupaten Ciamis memfokuskan Program Pengembangan Destinasi Pariwisata di Situ Lengkong sebagai objek wisata yang paling banyak dikunjungi oleh wisatawan dari tahun 2014-2015. Setelah pelaksanaan program ternyata jumlah PAD yang dihasilkan pada tahun 2015 hanya mencapai 35,99\% dari yang ditargetkan. Temuan tersebut merupakan suatu masalah dari pelaksanaan program tersebut yang disebabkan karena tidak efektifnya program tersebut. Teori yang digunakan yakni teori Efektivitas Program dari Kettner, Moroney dan Martin (2008), beliau mengemukakan bahwa untuk menilai efektivitas program dapat diukur dari Upaya, Efisiensi Biaya, Hasil, Efektivitas Biaya, dan Dampak. Penelitian ini dilakukan dengan menggunakan metode deskriptif serta pendekatan kualitatif. Data diperoleh dengan melalui studi kepustakaan serta studi lapangan yang berupa observasi non-partisipatif, wawancara mendalam, dan dokumentasi. Pengujian kredibilitas data menggunakan teknik triangulasi sumber dan triangulasi teknik, kemudian data-data tersebut direduksi, disajikan, dan ditarik simpulan. Berdasarkan hasil penelitian, nyatanya pelaksanaan program tersebut belum efektif dalam mencapai tujuannya yakni capaian PAD sesuai target. Belum efektifnya program disebabkan oleh adanya keterbatasan upaya-upaya dan anggaran dalam mengembangkan Situ Lengkong sesuai kebutuhan dilapangan oleh Dinas Pariwisata dan Ekonomi Kreatif Kabupaten Ciamis.
\end{abstract}

Kata Kunci: Efektivitas Program, Program Pengembangan Destinasi Pariwisata, Situ Lengkong, Pendapatan Asli Daerah (PAD) Kabupaten Ciamis.

\section{ABSTRACT}

This paper seeks to present the results of research that describes how the Tourism Destination Development Program Effectiveness in Ciamis (A Study of Situ Lengkong Attractions). This research is based on the fact of declined in local revenue (PAD) Ciamis District of the tourism sector after the Pangandaran separates into New Autonomous Region. However, the Government of Ciamis district development program focusing on the tourism destination attraction Situ Lengkong as the most visited by tourists from the years 2014-2015. After the implementation of the program turned out to be the amount of revenue generated in 2015 reached only 35.99\% of the target. The findings indicate the 
ineffectiveness of the program. The theory used is the effectiveness theory of the program by Kettner, Moroney and Martin (2008), he argued that in order to assess the effectiveness of the program can be measured by Effort, Cost Efficiency, Results, Cost Effectiveness, and Impact. This research is conducted by using descriptive and qualitative approach. Data obtained through literature and field studies in the form of non-participatory observation, indepth interview, and documentation. Testing the credibility of the data using triangulation of sources and triangulation techniques, then the data is reduced, presented, and the conclusions were drawn. Based on the results of research, in fact, the implementation of the program has not been effective in achieving its objectives of local revenue target. The ineffectiveness of the program due to the limitations of efforts and budgets in developing Situ Lengkong according to the needs in the field by the Department of Tourism and Creative Economy Ciamis District.

Keywords: Effectiveness Program, Tourism Destination Development Program, Situ Lengkong, Local Rrevenue (PAD) Ciamis District.

\section{PENDAHULUAN}

Kabupaten Ciamis merupakan Kawasan Strategis Pariwisata Provinsi Jawa Barat. Sebagai salah satu KSPP di Jawa Barat maka Kabupaten Ciamis memiliki pendapatan asli daerah yang cukup besar dari sektor pariwisata. Namun sejak Pangandaran memisahkan diri menjadi daerah otonomi baru Tahun 2013, maka Kabupaten Ciamis kehilangan cukup banyak PAD. Maka dari itu sejak tahun 2014, Pemerintah Daerah Kabupaten Ciamis berusaha memfokuskan program pengembangan destinasi pariwisata untuk mengembangkan objek wisata yang salah satunya adalah Situ Lengkong sebagai salah satu objek wisata yang paling banyak dikunjungi oleh wisatawan dari tahun 2014 sampai 2015. Program tersebut bertujuan untuk mencapai tujuan Dinas Pariwisata dan Ekonomi Kreatif Kabupaten Ciamis sebagaimana tertera dalam Rencana Strategis Tahun 20142019.

\section{METODE PENELITIAN}

Untuk memahami mengapa Program Pengembangan Destinasi Pariwisata di Situ Lengkong belum efektif maka Peneliti menggunakan metode penelitian kualitatif. Peneliti menganggap bahwa metode penelitian kualitatif relevan digunakan sebagai metode dalam penelitian ini. Hal tersebut diarenakan fenomena yang terjadi tidak memungkinkan diukur secara tepat (dikuantifikasi), sehingga untuk mendapatkan pemahaman yang tepat diperlukan eksplorasi kepada para informan. Melalui metode penelitian kualitatif ini, Peneliti dapat mengkaji perspektif informan yang memiliki otoritas, data, informasi, serta keterkaitan lainnya dalam progam pengembangan destinasi pariwisata di Situ Lengkong. Pengkajian perspektif informan bertujuan untuk memahami fenomena-fenomena sosial dari perspektifnya. Selain itu juga dapat mengetahui permasalahan dari efektivitas program pengembangan destinasi pariwisata di Kabupaten Ciamis oleh Dinas Pariwisata dan Ekonomi Kreatif Kabupaten Ciamis dengan melihat fenomena yang ada melalui data-data yang diperoleh agar dapat dideskripsikan secara menyeluruh, terperinci dan akurat sesuai dengan kenyataan yang ada di lapangan. Kemudian kemudian disusun dan dianalisis sehingga dapat ditarik kesimpulan yang dapat menggambarkan suatu masalah yang sedang terjadi. Pendekatan penelitian deskriptif pun meliputi penjelasan mengenai data yang dikumpulkan, sehingga dapat menjelaskan kompleksitas suatu permasalahan. Data diperoleh dengan menggunakan studi kepustakaan dan studi 
lapangan berupa observasi nonpartisipatif, wawancara mendalam, serta dokumentasi. Teknik pengujian kredibilitas data menggunakan teknik triangulasi sumber dan triangulasi teknik, kemudian data-data tersebut direduksi, disajikan, dan ditarik simpulan.

\section{HASIL DAN PEMBAHASAN}

Hasil penelitian yang Penulis lakukan menunjukkan bahwa: 1) Program pengembangan destinasi pariwisata di Situ Lengkong telah dilaksanakan melalui 3 kegiatan didalamnya yait peningkatan pengembangan saran dan prasarana, pemeliharaan fasilitas objek wisata sertamonitoring dan evaluasi. Namun pelaksanaan semua kegiatan tersebut terkendala oleh anggaran dan sumberdaya manusia dalam pelaksanannya; 2) Pelaksanaan program ditinjau dari upaya nampaknya upaya yan dilakukan oleh Dinas Pariwisata dan Ekonomi Kreatif untuk mencapai tujuan dinas pada program ini belum berjalan sebagaimana kebutuhan dilapangan; 3) Dari aspek efisiensi biaya, nyatanya peluang dengan keberadaan UPT Wilayah Panjalu belum mampu memberikan nilai bantu guna menefisienkan biaya dalam pelaksanaan kegiatan monitoring dan evaluasi sehingga indikator capaian kegiatan monitoring dan evaluasi tidak tercapai secara maksimal; 4) Dari aspek hasil pun 3 kegiatan memang sudah terlaksana namun belum dapat menghasilkan capaian tujuan program; 5) Dari aspek Efektivitas biaya, biaya yang dikeluarkan untuk melaksanakan kegiatan ini memang cukup besar tetapi hal tersbeut tidak berbanding lurus dengan capaian tujuan yang masih sangat jauh dari target yang ditetapkan; 6) Dari aspek dampak, nampaknya keberadaan pariwisata Situ Lengkong memang memberikan dampak yang positif pada pemasukan PAD bagi pemerintah daerah Kabupaten Ciamis serta dapat menmbangkitkan gairah usaha masyarakat sekitar Panjalu. Namun bagi pemerintah daerah dan masyarakat sendiri, dampak yang ditimbulkan masih belum cukup memberikan kontribusi yang lebih besar. Hal tersebut dapat dilihat dari capaian PAD sebesar Rp. 330.588 .750 yang hanya berkontribusi sebesar $0,20 \%$ dari total PAD Kabupaten Ciamis pada Tahun 2015. Begitupun juga dengan masyarakat, sampai tahun 2015 mayoritas pekerjaan masyarakat Panjalu masih pada sektor pertanian sehingga keberadaan pariwisata Situ Lengkong belum mampu mendongkrak gairah usaha masyarakat secara lebih besar.

\section{SIMPULAN DAN SARAN}

Berdasarkan hasil penelitian yang telah Penulis paparkan pada bab sebelumnya, dapat disimpulkan bahwa Efektivitas Program Pengembangan Destinasi Pariwisata di Situ Lengkong oleh Dinas Priwisaa dan Ekonomi Kreatif Kabupaten Ciamis belum efektif, karena tujuan program tidak dapat tercapai dilihat dari 5 aspek yaitu upaya, efisiensi biaya, hasil, efektivitas biaya serta dampak. Penyebab ketidakefektifan program tersebut yakni karena adanya keterbatasan anggaran dan sumebrdaya manusia dalam pelaksanannya.

Adapun saran yang Penulis rekomendasikan agar ke depannya program pengembangan destinasi pariwisata dapat berjalan lebih efektif yakni mencari alternatif pembiayaan lain baik dari pemerintah pusat, provinsi mapun kerjasama dengan swasta untuk mengembangkan Situ Lengkong. Kedua yakni melakukan pengkajian karakteristik budaya sekitar Situ Lengkong sebagai dasar pertimbangan dalam pengembangan wisata Situ Lengkong. Serta merangkul masyarakat sekitar yang memanfaatkan usaha pariwisata di Situ Lengkong untuk memasarkan produk khas Ciamis secara komprehensif agar masyarakat lebih mengali potensi usahanya baik kuliner atau merchandise wisata. Dengan begitu masyarakat akan lebih terpacu gairah usahanya serta akan dapat menjadi sarana 
promosi agar Kabupaten Ciamis lebih dikenal masyarakat luar.

\section{UCAPAN TERIMA KASIH}

Peneliti menyadari bahwa tanpa bantuan serta bimbingan dan arahan dari berbagai pihak dari tahap awal hingga akhir penyusunan Skripsi ini, tentu akan dirasa sangat sulit bagi Peeliti untuk menyelesaikannya. Oleh karena itu, Peneliti menghaturkan terima kasih sebesar-besarnya serta penghormatan setinggi-tingginya kepada pihak-pihak yang telah berkenan membantu Peneliti dalam menyelesaikan penyusunan Skripsi ini.

\section{DAFTAR PUSTAKA}

\section{Buku}

Djafar, Suaib. 2013. Kebijakan

Pengembangan Pariwisata Pulau

Togian Kabupaten Tojo Una Una

Provinsi Sulawesi Tengah. Bandung:

LP3AN Fisip Unpad

Handayaningrat, Soewarno. 1985.

Pengantar Ilmu Amdinistrasi dan

Manajemen. Jakarta: CV Haji

Masagung.

Jones, Charles O. 1991. Pengantar

Kebijakan Publik. Jakarta:

Penerjemah Nashir Budiman: CV Rajawali

Kunardjo, 2002. Perencanaan dan

Pengendalian Program

Pembangunan. UI Press, Jakarta

Kraft, Michael E dan Scott R Furlong. 2010. Public Policy: Politics, Analysis and Alternative. Washington DC: CQ Press.

Makmur. 2011. Efektivitas Kebijakan Kelembagaan Pengawasan. Bandung: PT. Refika Aditama.

Matland, Richard E. 1995. Synthezing the Implementation Literature: The
Ambiguity-Conflict Model of Policy Implementation. Oxford University Press

Moleong, Lexy J. 2007. Metode Penelitian Kualitatif. Bandung: PT. Remaja Rosdakarya Offset.

Nugroho, Riant. 2011. Public Policy. Jakarta; Elex Media

Peter M, Kettner, Robert M Moroney dan Lawrence L. Martin. 2008.

Designing and Managing Programs: An Effectiveness-Bassed Approach. United States of America: Sage Publications, Inc

Rusli, Budiman. 2013. Kebijakan Publik: Membangun Pelayanan Publik yang Responsif. Bandung: Hakim Publishing.

Siagian, Sondang P. 2001. Manajemen Strategik. Jakarta: Bumi Aksara.

Silalahi, Ulbert. 2006. Metode Penelitian Sosial. Bandung: Unpar Press.

Sugiyono. 2009. Metode Kuantitatif, Kualitatif dan R\&D. Bandung: Alfabeta.

Sugiyono. 2010. Metode Penelitian Administrasi. Bandung: Alfabeta.

Syafiie, Inu Kencana. 2010. Ilmu Administrasi Publik. Jakarta: Rineka Cipta.

Tachjan, H. 2006. Implementasi Kebijakan Publik. Bandung: Truen RTH.

Tchjan H. 2008. Implementasi Kebijakan Publik. Bandung: AIPI BandungPuslit KP2W Lemlit Bandung. 
Thoha, Miftah. 2005. Dimensi-dimensi

Prima Ilmu Amdinistrasi Negara:

Jakarta:

PT Raja Grafindo.

Tjokroaminoto, Bintoro. 1995.

Pengantar Administrasi

LP3ES.

Pembangunan. Jakarta:

\section{Dokumen Peraturan Perundang- \\ Undangan}

Undang-Undang Republik Indonesia

Nomor 10 Tahun 2009 Tentang

Kepariwisataan

Peraturan Derah provinsi Jawa Barat

Nomor 15 Tahun 2015 Tentang

Rencana Induk Pembangunan

Kepariwisataan Provinsi Jawa Barat

Tahun 20152025

Sumber Dokumentasi

Rencana Strategis Dinas Pariwisata

Kabupaten Ciamis 2014-2019

Rencana Kerja Dinas Pariwisata

Kabupaten Ciamis Tahun 2014

Rencana Kerja Dinas Pariwisata

Kabupaten Ciamis Tahun 2015

Laporan Akuntabilitas Kinerja Instansi

Pemerintah (LAKIP) Dinas

Pariwisata dan Ekonomi Kreatif

Kabupaten Ciamis Tahun 2014

Laporan Akuntabilitas Kinerja Instansi

Pemerintah (LAKIP) Dinas

Pariwisata dan Ekonomi Kreatif

Kabupaten Ciamis Tahun 2015

\section{Sumber Lain}

Rahmaini, Yulia. 2014. Implementasi

Program Pengembangan Destinasi

Pariwisata di Kampung Wisata Pasir

Kunci Kelurahan Pasirjati

Kecamatan Ujung Berung oleh

Dinas Kebudayaan dan Pariwisata

Kota Bandung. Skripsi Administrasi

Publik. Universitas Padjadjaran.
Richardo Nego, Gerry. 2016. Efektivitas Program Pengembangan Pemasaran Pariwisata Di Kota Bandung. Skripsi Administrasi Publik. Universitas Padjadjaran.

Subagyo, Ahmad Wito. 2000. Efektivitas Program Penanggulangan Masyrakat Perdesaan. Tesis Universitas Gadjah Mada.

\section{Sumber Online}

Website Provinsi Jawa Barat. Provinsi Jawa Barat Dalam Angka 2012. Diambil kembali dari jabarprov.go.id: http://www.jabarprov.go.id/root/dala mangka/dda2012.pdf.

Republika.co.id. (2015, Mei 17).

Website BPS Provinsi Jawa Barat. Provinsi Jawa Barat Dalam Angka 2014. Diambil kembali dari jabarbps.go.id: http://jabar.bps.go.id/new/website/pd f_publikasi/Jawa-BaratDalamAngka-2014.pdf

Website Pusdalisbang Provinsi Jawa Barat. Provinsi Jawa Barat Dalam Angka 2015. Diambil kembali dari pusdalisbang.jabarprov.go.id: http://pusdalisbang.jabarprov.go.id/p usdalisbang/berkas/j bardalamangka/54Jawa-BaratDalam-Angka-2015.pdf

Website Dinas Pariwisara dan Kebudayaan Provinsi Jawa Barat. Provinsi Jawa Barat Dalam Angka 2015. Diambil kembali dari disparbud.jabarprov.go.id: http://www.disparbud.jabarprov.go.i $\mathrm{d} /$ applications/fronted/index.php?mo $\mathrm{d}=$ statistik-wisatawan

Website Provinsi Jawa Barat. Provinsi Jawa Barat Dalam Angka 2016. 


\section{JURNAL ADMINISTRASI NEGARA}

Volume 2. No 1, Agustus 2017

Diambil kembali dari

pusdalisbang.jabarprov.go.id:

http://pusdalisbang.jabarprov.go.id/p

usdalisbang/berkas/jabardalamangka

747Provinsi-Jawa-Barat-Dalam-

Angka-2016.pdf 